\title{
Prevention and management of pain and stress in the neonate
}

\author{
This article was published in the following Dove Press journal: \\ Research and Reports in Neonatology \\ 7 January 2015 \\ Number of times this article has been viewed
}

\author{
Denise Harrison ${ }^{1,2}$ \\ Mariana Bueno ${ }^{3}$ \\ Jessica Reszel ${ }^{2}$ \\ 'School of Nursing, University \\ of Ottawa, Ottawa, ON, Canada; \\ ${ }^{2}$ Children's Hospital of Eastern \\ Ontario and Children's Hospital of \\ Eastern Ontario Research Institute, \\ Ottawa, ON, Canada; ${ }^{3}$ Department \\ of Maternal Child and Psychiatric \\ Nursing, School of Nursing, University \\ of São Paulo, São Paulo, Brazil
}

Correspondence: Denise Harrison Children's Hospital of Eastern Ontario, 40I Smyth Road, Ottawa, ON, Canada, $\mathrm{KIH} 8 \mathrm{LI}$

Tel + I 6137377600 ext $4 \mid 40$

$\mathrm{Fax}+\mathrm{I} 6137376504$

Email dharrison@cheo.on.ca
Abstract: Neonates have blood work for newborn screening in their first days of life, and preterm and sick hospitalized infants often require repeated invasive needle-related procedures over the duration of their hospitalization. Reducing newborn infants' pain during such painful procedures is important and may reduce the risk of negative sequela of poorly treated procedural pain. High-quality synthesized evidence demonstrates analgesic effects of three pain management strategies: breastfeeding; skin-to-skin care, also referred to as kangaroo care; and small amounts of sweet solutions. These strategies are simple to use, easily accessible, and extremely cost-effective. Published neonatal and infant pain guidelines include recommendations to use these strategies prior to and during painful procedures. Yet, despite the robust evidence and pain management recommendations in guidelines and national and international organizations, knowledge has not been translated into consistent normalized care in diverse maternal newborn, neonatal, and pediatric settings where painful procedures for infants take place. There may be knowledge gaps or barriers impeding consistent use of effective pain management for newborn infants. This paper will present a brief review of methods used to assess neonatal pain, followed by a summary of the evidence supporting breastfeeding, skin-to-skin care, and sweet solutions for procedural pain reduction with a discussion about barriers and facilitators to using these strategies in the clinical setting. Finally, a review of recommendations included in current neonatal pain guidelines will be presented.

Keywords: infant, pain management, breastfeeding, skin-to-skin care, sucrose

\section{Introduction}

Almost all neonates have blood work for newborn screening in their first days of life, and preterm or sick hospitalized infants may require repeated invasive needle-related procedures for medical monitoring over the course of their hospitalization. ${ }^{1-4}$ The publication of an increasing number of studies in recent years linking repeated neonatal pain exposure with poor neurological outcomes is concerning, ${ }^{5-9}$ and highlights the urgent need for health care professionals and parents of healthy, preterm, and sick neonates, to reduce pain exposure and to advocate for consistent use of effective pain management strategies.

The encouraging news is that health care providers (HCPs) now have well-validated means of assessing pain ${ }^{10}$ and simple, feasible, and effective ways to reduce pain during needle-related painful procedures. Breastfeeding (BF), ${ }^{11}$ skin-to-skin care (SSC), also referred to as kangaroo mother care, ${ }^{12}$ and sweet solutions; either sucrose ${ }^{13}$ or glucose,${ }^{14}$ reduce pain during commonly performed painful procedures compared to no treatment, water, breast milk, or positioning, swaddling, holding, or cuddling. 
HCPs and parents now have effective pain-reducing strategies available to use for neonatal pain - the next step is to ensure that these strategies are consistently used during necessary painful procedures.

This paper will present an overview of indicators used to assess pain in the neonate, a review of the evidence supporting $\mathrm{BF}, \mathrm{SSC}$, and sweet solutions for procedural pain reduction, and recommendations included in neonatal pain management guidelines.

\section{Pain indicators}

Extensive research by multiple professions including nursing, psychology, basic science, and medicine, focusing on neonatal pain measurement has been conducted over the past 20 years. ${ }^{10}$ The most frequently used indicators of neonatal pain for clinical care and research purposes are behavioral indicators - most commonly, facial expressions and crying. Nearly all composite pain assessment tools developed include one or both of these behavioral indicators. The first identified systematic descriptions of infants' facial expressions during periods of crying were by Charles Darwin, using a series of photographs accompanying written explanations of the facial muscles involved in the formation of expressions of distress. ${ }^{15}$ Over a century later, authors of the neonatal facial coding system categorized ten facial expressions in response to heel lancing, with the four most frequently occurring facial expressions of brow bulge, eye squeeze, nasolabial furrow, and open lips described as the most specific behavioral indicators of acute procedural pain in infants regardless of gestational age or severity of illness. ${ }^{16-18}$ These four facial expressions form the basis of the majority of the more than 40 composite uni- or multidimensional published pain assessment tools used to quantify the existence and intensity of pain in neonates. ${ }^{19,20}$

Crying incidence and duration, although unable to be assessed in neonates with endotracheal or tracheostomy tubes, are also frequently used as behavioral indicators of pain. For example, in the systematic review of sucrose for neonatal procedural pain, crying duration was used as an outcome measure in 35 (61\%) of the 58 included studies. ${ }^{13}$ The acoustic characteristics of a newborn's cry such as pitch and amplitude have been studied in the past; ${ }^{21-23}$ however, they are rarely used in clinical care or clinical research due to the need for specialized equipment as well as the lack of specificity to pain, especially in preterm and sick infants with altered crying characteristics. Physiological responses to painful procedures are less sensitive and specific to procedural pain than behavioral indicators, and are highly influenced by health status. However, they are also frequently used in studies evaluating interventions for reducing pain in neonates and are included in many composite and multidimensional pain assessment tools. The most commonly included parameters are heart rate, oxygen saturation levels, and respiratory rate and pattern. In the search for reliable objective specific indicators of pain, numerous other indicators of neonatal pain have also been explored. These include: heart rate variability, ${ }^{24}$ skin conductance, a measure of sympathetic nervous system activation due to the release of sweat in response to stress, ${ }^{25-28}$ stress hormone levels, such as serum, salivary, urinary, or hair cortisol; ${ }^{29-31}$ and neural activity such as electroencephalography $(\mathrm{EEG})^{32,33}$ or cerebral near-infrared spectroscopy (NIRS). ${ }^{34}$ Despite the multitude of indicators of pain in newborns that have been identified and explored to various degrees, questions remain about the validity, reliability, and specificity of these different pain indicators. A lack of convergence of behavioral, physical, hormonal, and cortical responses ${ }^{35}$ further highlight the complex nature of pain assessment and ongoing research questions to address. While further research is being planned and conducted to continue to evaluate neonatal pain assessment methods and indicators to use in research and clinical care over the spectrum of neonatal care, in the meantime, clinicians are faced with decisions about the best pain assessment method to use. The best answer currently is - use a pain assessment method that is:

- already developed and tested in the clinical area

- suitable for the specific unit/setting/population

- feasible to use

- acceptable to staff

- used consistently

- used in ward rounds, handovers, and in clinical care to make decisions about pain management.

When planning to introduce a new pain assessment method or composite measurement tool, it is important that the bedside clinicians are involved in the decision-making process about which tools are the most suitable for their patient population. Once the decision has been made, providing initial and ongoing education to ensure all HCPs are familiar with the use of the pain assessment tools is vital for integrating pain assessment into normalized practice.

In addition to the need for further exploration of issues surrounding the measurement of pain, clinically important challenges are also to: i) reduce pain exposure, and ii) consistently utilize effective pain reduction strategies in diverse settings where painful procedures take place. Recommendations aimed at reducing neonatal procedural pain need to start 
with minimizing pain exposure. Worryingly, despite the often quoted study by Barker et al nearly two decades ago in 1995, which showed that for a cohort of 54 infants in a neonatal intensive care unit (NICU), over 3,000 procedures were performed, the large majority being heel lances, ${ }^{36}$ more recently published studies continue to report large numbers of painful procedures with suboptimal use of effective pain management strategies. ${ }^{1-4,37-47}$ Such large numbers of painful procedures continue to occur despite the trend in the last decade toward use of less invasive respiratory support. ${ }^{48}$ Although respiratory support-related procedures such as endotracheal intubations and airway suctioning have decreased, Axelin et al reported that the number of heel lances actually increased. ${ }^{48}$ This situation highlights the need for HCPs to balance the need for close monitoring of preterm and sick neonates' pathology with efforts to minimize exposure to painful procedures.

When painful procedures are necessary, however, evidence-based pain reduction strategies are available. Highquality synthesized evidence shows that BF, SSC, and sweet solutions - either sucrose or glucose, effectively reduce pain during commonly performed needle-related painful procedures. ${ }^{11-14,49}$ These three strategies are effective, feasible, simple to use, and cost-effective. If the mother is able to participate, BF and SSC during blood collection are free, and sucrose is inexpensive. Sucrose made by hospital pharmacies costs approximately 45 cents/dose (R Vaillancourt, personal communication, 2013) and manufactured sucrose (TootSweet $24 \%$ ) costs \$1/unit (currency in Canadian dollars).

The following section will review the evidence for these three strategies, facilitators and barriers to using each strategy in clinical care, and recommendations for practice.

\section{Breastfeeding}

A Cochrane systematic review of BF or breast milk for procedural pain management demonstrated analgesic effects of BF for medically stable newborn infants during heel lance and venipuncture. ${ }^{11}$ Twenty trials were included; ten of which evaluated BF and ten studied analgesic effects of small volumes of breast milk. Comparators included no treatment, placebo, sweet solutions, non-nutritive sucking, holding, and positioning. Overall, findings were that BF effectively reduced behavioral and physiological responses and composite pain scores during or following painful procedures. However, small volumes of breast milk were ineffective in reducing pain. The mechanism of action of $\mathrm{BF}$ is considered to be multifactorial, combining maternal SSC, ${ }^{50}$ sucking and slightly sweet taste, ${ }^{51}$ as well as the presence of endorphins in the breast milk. ${ }^{52-54}$ However, lactose, the sugar in breast milk, is the least sweet of the four sugars, ${ }^{55}$ and therefore has minimal sweet taste-mediated analgesic effects when used in isolation. The conclusions of the systematic review were that if the mother is available, BF should be used during painful procedures where feasible.

\section{Facilitators and barriers to implementation}

$\mathrm{BF}$ is a simple and cost-effective method of pain reduction for neonates during non-urgent procedures such as newborn screening or routine bloodwork performed by heel lance and venipuncture. As long as the mother is available, BF requires no additional resources (ie, cost or equipment) and can thus be implemented in diverse settings (such as hospitals, clinics, and in the home). Yet, despite the evidence, BF has not been consistently implemented in clinical practice. ${ }^{38,42}$ In a Canadian-wide study of pain management practices in NICUs, Johnston et $\mathrm{al}^{3}$ showed that of the 582 neonates in their study, almost half received no pain management during skin-breaking procedures, and only $0.03 \%$ of infants were breastfed during bloodwork. Barriers to using BF for pain management, especially in preterm and/or sick neonates in NICUs may include delayed or impaired sucking reflex, ${ }^{56}$ separation from the mother, ${ }^{42}$ as well as the need for further evidence of effectiveness and feasibility in this population. ${ }^{11}$ Other barriers include lack of awareness of the benefits, parents not being aware of the possibility of participating in pain management, and HCPs' lack of knowledge of the evidence and beliefs surrounding BF during painful procedures, such as: the baby will associate feeding with pain and BF during painful procedures will cause the baby to choke. ${ }^{57}$ Organizational factors such as the need to schedule nonurgent blood work around the availability of the mother and ergonomic factors such as having the nursing or laboratory staff change positions to accommodate drawing blood during $\mathrm{BF}$, have also been identified as barriers to implementing this strategy. ${ }^{38}$

\section{Skin-to-skin care}

Johnston et al recently published a Cochrane systematic review of the effectiveness of SSC for pain management during painful procedures. ${ }^{12}$ The systematic review included 19 studies and a total of 1,594 infants. The majority of the included studies examined heel lance ( $\mathrm{n}=15,744$ infants), and the remaining studied SSC during venipuncture and heel lance combined, and intramuscular injection. Fifteen studies included preterm infants and four included full-term 
infants. Eleven of the studies compared SSC with the mother to a no treatment control group, while the other studies' comparators included SSC with other family members; sucrose or other sweet solutions; BF; or enhanced SSC (rocking, singing, talking, non-nutritive sucking). There was significant heterogeneity across the studies, including wide variations in the dose of SSC prior to the procedures, outcome measures used, and timing of measurement of outcomes. These factors limited pooling of the results across the studies. Overall, SSC with the mother had variable effects but in most studies, was more effective than no treatment. The authors concluded that SSC is safe, and a potentially beneficial method of reducing physiological and behavioral responses in neonates during heel lance, venipuncture, and intramuscular injections.

\section{Facilitators and barriers to implementation}

Similar to BF, SSC is a cost-effective method for pain management, requiring only the mother or another caregiver to hold the infant against their skin, facilitating implementation in diverse settings. Factors influencing implementation of SSC during painful procedures have been examined and include a positive effect of HCPs' perception of the physiologic stability of the infant ${ }^{58-60}$ and the level of experience of the nurse, with more experienced nurses more likely to implement SSC during painful procedures. ${ }^{58}$ However, use of SSC in practice may be hindered by several factors. SSC requires that the mother or other caregiver be present for the painful procedure; therefore, non-urgent procedures need to be scheduled accordingly. ${ }^{38}$ In addition, there may be the perception that implementing SSC is not feasible as it takes additional time to prepare the infant and parent for SSC. ${ }^{38,60}$ Environmental factors such as dim lighting and lack of privacy for caregivers, as well as ergonomic factors such as challenges to drawing blood while the infant is in SSC have also been identified. . $^{3,56,60}$

\section{Sweet solutions}

Sweet solutions are the most frequently investigated strategy for neonatal pain relief. There are now more than 200 published studies reporting calming and analgesic effects of sweet-tasting solutions in infants, the large majority of which are placebo-controlled trials. ${ }^{49,61,62}$ Although the exact mechanism remains uncertain, effects are considered to be orally mediated through endogenous opioid mechanisms, with reversal of effects by administration of opioid receptor antagonists. ${ }^{54,63-65}$ Analgesic effects of sweet solutions are considered to be taste-dependent, with the sweetest solutions providing more effective pain relief. ${ }^{55}$ Sucrose, a disaccharide (glucose and fructose) is the sweetest of the sugars (sucrose $>$ fructose $>$ glucose $>$ lactose) $)^{55}$ and the most effective when compared to less sweet solutions. ${ }^{49}$ However, glucose, if administered in sufficient concentrations, eg, 20\%-30\%, is also considered as an effective alternative. $^{14}$

Two large systematic reviews, including 57 studies of sucrose ${ }^{13}$ and 39 studies of glucose, ${ }^{14}$ highlight the extensive and rigorous evidence of sweet taste-induced analgesia for neonatal pain reduction. The results of both systematic reviews demonstrated consistent reduction of behavioral parameters and composite pain scores compared to no treatment groups, water, small volumes of breast milk or formula milk, and non-nutritive sucking during heel lancing and venipuncture, as well as less frequently studied painful procedures such as gastric tube insertions or arterial punctures. However heterogeneity in outcome measures across studies included in both systematic reviews precluded broad pooling of results. ${ }^{13,14}$ Furthermore, although sucrose or glucose consistently reduce behavioral responses during painful procedures compared to no treatment, placebo, or less sweet solutions, physiological indicators and stress hormone responses are inconsistently affected by sweet solutions. In addition, two studies examining the effects of sweet solutions on cortical responses showed no effects compared to placebo. ${ }^{32,33,66}$ Norman et $\mathrm{al}^{33}$ concluded that EEG was not a useful measure of cortical brain activity in newborn infants, yet Slater et al concluded that further analgesic studies using cortical measures of pain as outcomes measures were warranted. ${ }^{32}$ Weak correlations between indicators of pain, direction, and degree of responses have long been reported, ${ }^{67}$ highlighting challenges in interpreting and making decisions about the implementation of research findings. However, the extensive research conducted over the past 25 years provides indisputable evidence that small volumes of sweet solutions significantly reduce behavioral responses and composite pain scores to painful procedures in newborn and young infants. ${ }^{35}$ It can therefore be argued that a condition of clinical equipoise, a requirement for conducting ethical placebo-controlled trials, has not been in existence since the publication of the international consensus statement of neonatal pain management in 2001. 49,68 In response to this statement, calls have been made to cease further conduct of placebo-controlled trials of sweet solutions for single episodes of painful procedures for neonatal pain. . $^{4,61,62,69,70}$ 
However, uncertainties and important research questions still remain:

- What are the exact mechanisms of analgesic effects of sweet solutions?

- Does consistent use of sweet solutions as required, during repeated painful procedures, ameliorate negative sequela of procedural pain exposure?

- Are sweet solutions efficacious when used in the context of exogenous opioids?

- What is the minimal effective volume required for analgesic effects?

Addressing these remaining key knowledge gaps need to be prioritized in future research on sweet solutions for analgesia.

\section{Facilitators and barriers to implementation}

Sucrose or glucose solutions are simple to use and costeffective, and maximum analgesic effects are rapidly achieved after delivering the solution onto the tongue (1-2 minutes), ${ }^{35,71}$ facilitating its use before scheduled and non-scheduled painful procedures. Ensuring availability and easy accessibility in diverse postnatal and neonatal settings where bloodwork, immunizations, and other painful procedures take place is vital for facilitating consistent use during painful procedures. Many hospital pharmacies now produce their own sucrose solutions, and commercially manufactured sucrose solutions are available for purchase. Glucose is commonly available in clinical settings for intravenous use and can be orally administered prior to and during painful procedures.

Remaining knowledge gaps, however, may be acting as barriers to adoption of sweet solutions into normalized care. In addition, despite the prolific research conducted to date, repeated doses of sweet solutions over prolonged periods have only been investigated in a small number of studies. ${ }^{72-75}$ Although these studies showed ongoing effectiveness of sucrose over weeks to months of use, further research in this area, especially with the aim of exploring if consistently reducing procedural pain over prolonged hospitalizations ameliorates negative sequela of untreated pain for preterm and high-risk neonates, will add valuable information to the science of neonatal pain management.

\section{Recommendations for practice and clinical practice guidelines}

Over the past decade, increasing numbers of clinical practice guidelines (CPG) focusing on, or including neonatal and infant pain management, have been developed at the level of individual organizations, ${ }^{40,42,43}$ as well as at a national and international level. ${ }^{76-80} \mathrm{In}$ a recent systematic review of CPGs focusing on pain reduction in neonates, infants, and children, 18 published CPGs were identified, and seven specifically related to neonates or infants. ${ }^{80}$ Recommendations for this age group included minimizing the number of painful procedures, reducing environmental noise and light, using SSC or BF during painful procedures, and using sucrose with or without non-nutritive sucking.

A consistent and coordinated approach to improving neonatal pain management and implementing pain management recommendations included in nationally and internationally endorsed guidelines is called for. Such a coordinated effort requires commitment and engagement from all involved parties, including parents, HCPs from the level of frontline carers, through to organizational and professional association leadership, as well as administrators and consumer groups. ${ }^{80}$ To optimize effectiveness, knowledge translation (KT) efforts need to target HCPs as well as the parents of healthy, preterm, and hospitalized term infants. Strategies planned to support parents to advocate for their infants and participate in their infants' pain management during painful procedures need to include the parents of infants, particularly the mothers, if $\mathrm{BF}$ during routine non-urgent blood draws is to be promoted. To date, however, very little research has targeted parents of hospitalized infants as partners in pain management improvement initiatives, despite care being viewed as a partnership between HCPs and the family, ${ }^{81,82}$ and parents expressing the need to be more involved in comforting their infants during painful procedures ${ }^{83,84}$ In addition, in a Canada-wide study, infants in the NICU whose mothers were present during painful procedures were more likely to receive effective pain management strategies than those infants whose mothers were not present, ${ }^{3}$ highlighting a positive influence of parents. There is therefore a clear need for developing and testing acceptable parent-targeted interventions, alongside HCP-targeted KT interventions, to support parents to be involved in comforting their infants and to increase use of $\mathrm{BF}, \mathrm{SSC}$, and sucrose during painful procedures. An example of such an intervention is a publicly accessible YouTube video, targeted at parents of infants, showing three scenarios; a mother BF, a mother holding her infant in SSC during heel lance, and an infant being given sucrose with non-nutritive sucking during a venipuncture procedure (http://tinyurl. com/BSweet2newborns). The effectiveness of this YouTube video and other interventions disseminated via social media are potentially promising methods to widely disseminate knowledge. Research is warranted on the reach, impact, and 
effectiveness of using social media avenues such as YouTube in changing practices.

\section{Conclusion}

In conclusion, extensive high-quality synthesized evidence demonstrates the analgesic effects of $\mathrm{BF},{ }^{11} \mathrm{SSC},{ }^{12}$ and sweet-tasting solutions during short-lasting acute painful procedures. ${ }^{13,14,49}$ The growing and concerning evidence of adverse effects of untreated neonatal pain ${ }^{5-9,85}$ behooves HCPs in partnership with parents of infants, to strongly advocate for consistently using suitable effective pain reduction strategies during necessary painful procedures. Focusing on KT of existing evidence, while conducting further research to address remaining key knowledge gaps, will help to ensure that no infant suffers unnecessary pain during painful procedures.

\section{Acknowledgments}

The authors wish to thank the Children's Hospital of Eastern Ontario Media House, and infants, parents, midwives, nurses, and physicians who participated in the production of the BSweet2newborns video.

\section{Author contributions}

All of the authors have made substantial contribution to the writing and final editing of this review, and meet all criteria for authorship as per the author guidelines of this journal. The authors have all contributed to the production and dissemination of the parent-targeted YouTube video (http:// tinyurl.com/BSweet2newborns).

\section{Disclosure}

The authors report no conflicts of interest in this work.

\section{References}

1. Carbajal R, Rousset A, Danan C, et al. Epidemiology and treatment of painful procedures in neonates in intensive care units. JAMA. 2008; 300(1):60-70.

2. Harrison D, Loughnan P, Manias E, Johnston L. Analgesics administered during minor painful procedures in a cohort of hospitalized infants: a prospective clinical audit. J Pain. 2009;10(7):715-722.

3. Johnston C, Barrington KJ, Taddio A, Carbajal R, Filion F. Pain in Canadian NICUs: have we improved over the past 12 years? Clin J Pain. 2011;27(3):225-232.

4. Stevens B, McGrath P, Ballantyne M, et al. Influence of risk of neurological impairment and procedure invasiveness on health professionals' management of procedural pain in neonates. Eur J Pain. 2010;14(7): 735-741.

5. Doesburg SM, Chau CM, Cheung TP, et al. Neonatal pain-related stress, functional cortical activity and visual-perceptual abilities in school-age children born at extremely low gestational age. Pain. 2013; 154(10):1946-1952.

6. Brummelte S, Grunau RE, Chau V, et al. Procedural pain and brain development in premature newborns. Ann Neurol. 2012;71(3):385-396.
7. Anand KJS, Palmer FB, Papanicolaou AC. Repetitive neonatal pain and neurocognitive abilities in ex-preterm children. Pain. 2013;154(10):1899-1901.

8. Grunau RE, Holsti L, Haley DW, et al. Neonatal procedural pain exposure predicts lower cortisol and behavioral reactivity in preterm infants in the NICU. Pain. 2005;113(3):293-300.

9. Walker SM, Franck LS, Fitzgerald M, Myles J, Stocks J, Marlow N. Long-term impact of neonatal intensive care and surgery on somatosensory perception in children born extremely preterm. Pain. 2009;141(1-2):79-87.

10. Lee GY, Stevens BJ. Neonatal and infant pain assessment. In: McGrath P, Stevens B, Walker S, Zempsky W, editors. Oxford Textbook of Paediatric Pain. Oxford, UK: Oxford University Press; 2014:353-369.

11. Shah PS, Herbozo C, Aliwalas LL, Shah VS. Breastfeeding or breast milk for procedural pain in neonates. Cochrane Database Syst Rev. 2012;12:CD004950.

12. Johnston C, Campbell-Yeo M, Fernandes A, Inglis D, Streiner D, Zee R. Skin-to-skin care for procedural pain in neonates. Cochrane Database Syst Rev. 2014;1:CD008435.

13. Stevens B, Yamada J, Ohlsson A. Sucrose for analgesia in newborn infants undergoing painful procedures. Cochrane Database Syst Rev. 2013;1:CD001069.

14. Bueno M, Yamada J, Harrison D, et al. A systematic review and metaanalyses of nonsucrose sweet solutions for pain relief in neonates. Pain Res Manag. 2013;18(3):153-161.

15. Darwin C. The Expression of the Emotions in Man and Animals. Appleton D and Company, editors. Chicago, IL: The University of Chicago Press; 1872.

16. Grunau RE, Craig DK. Pain expression in neonates: facial action and cry. Pain. 1987;28(3):395-410.

17. Johnston CC, Strada ME. Acute pain response in infants: a multidimensional description. Pain. 1986;24(3):373-382.

18. Grunau RE, Oberlander T, Holsti L, Whitfield MF. Bedside application of the Neonatal Facial Coding System in pain assessment of premature neonates. Pain. 1998;76(3):277-286.

19. Anand KJ, Stevens BJ, McGrath P, editors. Pain in Neonates and Infants. Edinburgh, UK: Elsevier; 2007.

20. Duhn LJ, Medves JM. A systematic integrative review of infant pain assessment tools. Adv Neonatal Care. 2004;4(3):126-140.

21. Fuller BF, Neu M, Smith M, Vojir CP. Testing a model of the nursing assessment of infant pain. Clin Nurs Res. 1999;8(1):69-83.

22. Runefors P, Arnbjornsson E, Elander G, Michelsson K. Newborn infants' cry after heel-prick: analysis with sound spectrogram. Acta Paediatr. 2000;89(1):68-72.

23. Fuller BF. Acoustic discrimination of three types of infant cries. Nurs Res. 1991;40(3):156-160.

24. Faye PM, De Jonckheere J, Logier R, et al. Newborn infant pain assessment using heart rate variability analysis. Clin J Pain. 2010;26(9): 777-782.

25. Storm H. Changes in skin conductance as a tool to monitor nociceptive stimulation and pain. Curr Opin Anaesthesiol. 2008;21(6): 796-804.

26. Storm H. Development of emotional sweating in preterms measured by skin conductance changes. Early Hum Dev. 2001;62(2):149-158.

27. Harrison D, Boyce S, Loughnan P, Dargaville P, Storm H, Johnston L. Skin conductance as a measure of pain and stress in hospitalised infants. Early Hum Dev. 2006;82(9):603-608.

28. Røeggen I, Storm H, Harrison D. Skin conductance variability between and within hospitalised infants at rest. Early Hum Dev. 2011;87(1):37-42.

29. Yamada J, Stevens B, de Silva N, et al. Hair cortisol as a potential biologic marker of chronic stress in hospitalized neonates. Neonatology. 2007;92(1):42-49.

30. Pokela ML, Koivisto M. Physiological changes, plasma beta-endorphin and cortisol responses to tracheal intubation in neonates. Acta Paediatr. 1994;83(2):151-156. 
31. Harrison D, Johnston L, Spence K, Gillies D, Nagy S. Salivary cortisol measurements in sick infants: a feasible and objective method of measuring stress? J Neonatal Nurs. 2005;11(1):10-17.

32. Slater R, Cornelissen L, Fabrizi L, et al. Oral sucrose as an analgesic drug for procedural pain in newborn infants: a randomised controlled trial. Lancet. 2010;376(9748):1225-1232.

33. Norman E, Rosén I, Vanhatalo S, et al. Electroencephalographic response to procedural pain in healthy term newborn infants. Pediatr Res. 2008;64(4):429-434.

34. Ranger M, Johnston CC, Limperopoulos C, Rennick JE, du Plessis AJ. Cerebral near-infrared spectroscopy as a measure of nociceptive evoked activity in critically ill infants. Pain Res Manag. 2011;16(5): 331-336

35. Harrison D, Beggs S, Stevens B. Sucrose for procedural pain management in infants. Pediatrics. 2012;130(5):918-925.

36. Barker DP, Rutter N. Exposure to invasive procedures in neonatal intensive care unit admissions. Arch Dis Child Fetal Neonatal Ed. 1995;72(1):F47-F48.

37. Stevens B, Abbott L, Yamada J, et al; CIHR Team in Children's Pain. Epidemiology and management of painful procedures in children in Canadian hospitals. CMAJ. 2011;183(7):E403-E410.

38. Harrison D, Bueno M, Abdulla K, et al. How often do we use breastfeeding, skin to skin care and sucrose to reduce neonatal procedural pain? Presented at: International Association for the Study of Pain (IASP) 15th World Congress on Pain; October 6-11; 2014; Buenos Aires, Argentina.

39. Harrison D, Joly C, Chretien C, et al. Pain prevalence in a pediatric hospital: Raising awareness during Pain Awareness Week. Pain Res Manag. 2014;19(1):e24-e30.

40. Taddio A, Yiu A, Smith RW, Katz J, McNair C, Shah V. Variability in clinical practice guidelines for sweetening agents in newborn infants undergoing painful procedures. Clin J Pain. 2009;25(2):153-155.

41. Cignacco E, Hamers J, van Lingen RA, et al. Neonatal procedural pain exposure and pain management in ventilated preterm infants during the first 14 days of life. Swiss Med Wkly. 2009;139(15-16):226-232.

42. Harrison D, Loughnan P, Johnston L. Pain assessment and procedural pain management practices in neonatal units in Australia. J Paediatr Child Health. 2006;42(1-2):6-9.

43. Foster J, Spence K, Henderson-Smart D, Harrison D, Gray P, Bidewell J. Procedural pain in neonates in Australian hospitals: a survey update of practices. J Paediatr Child Health. 2013;49(1):E35-E39.

44. Losacco V, Cuttini M, Greisen G, et al; ESF Network. Heel blood sampling in European neonatal intensive care units: Compliance with pain management guidelines. Arch Dis Child. Fetal Neonatal Ed. 2011;96(1):F65-F68.

45. Eriksson M, Gradin M. Pain management in Swedish neonatal units - a national survey. Acta Paediatr. 2008;97(7):870-874.

46. Robins J. "Post code ouch": a survey of neonatal pain management prior to painful procedures within the United Kingdom. J Neonatal Nurs. 2007;13(3):113-117.

47. Simons SHP, van Dijk M, Anand KS, Roofthooft D, van Lingen RA, Tibboel D. Do we still hurt newborn babies? A prospective study of procedural pain and analgesia in neonates. Arch Pediatr Adolesc Med. 2003;157(11):1058-1064.

48. Axelin A, Ojajärvi U, Viitanen J, Lehtonen L. Promoting shorter duration of ventilator treatment decreases the number of painful procedures in preterm infants. Acta Paediatr. 2009;98(11):1751-1755.

49. Harrison D, Bueno M, Yamada J, Adams-Webber T, Stevens B. Analgesic effects of sweet-tasting solutions in infants: current state of equipoise. Pediatrics. 2010;126(5):894-902.

50. Blass EM, Shide DJ, Zaw-Mon C, Sorrentino J. Mother as shield: differential effects of contact and nursing on pain responsivity in infant rats - evidence for nonopioid mediation. Behav Neurosci. 1995;109(2): 342-353.

51. Gray L, Miller LW, Philipp BL, Blass EM. Breastfeeding is analgesic in healthy newborns. Pediatrics. 2002;109(4):590-593.
52. Blass EM, Blom J. beta-Casomorphin causes hypoalgesia in 10-day-old rats: evidence for central mediation. Pediatr Res. 1996;39(2): 199-203.

53. Zanardo V, Nicolussi S, Carlo G, et al. Beta endorphin concentrations in human milk. J Pediatr Gastroenterol Nutr. 2001;33(2): $160-164$.

54. Ren K, Blass EM, Zhou Q, Dubner R. Suckling and sucrose ingestion suppress persistent hyperalgesia and spinal Fos expression after forepaw inflammation in infant rats. Proc Natl Acad Sci US A. 1997;94(4):1471-1475.

55. Blass EM, Smith BA. Differential effects of sucrose, fructose, glucose, and lactose on crying in 1- to 3-day-old human infants: qualitative and quantitative considerations. Dev Psychol. 1992;28(5):804-810.

56. McNair C, Campbell Yeo M, Johnston C, Taddio A. Nonpharmacological management of pain during common needle puncture procedures in infants: current research evidence and practical considerations. Clin Perinatol. 2013;40(3):493-508.

57. Taddio A, Chambers CT, Halperin SA, et al. Inadequate pain management during routine childhood immunizations: the nerve of it. Clin Ther. 2009;31 Suppl 2:S152-S167.

58. Johnson AN. Factors influencing implementation of kangaroo holding in a Special Care Nursery. MCN Am J Matern Child Nurs. 2007;32(1):25-29.

59. Engler AJ, Ludington-Hoe SM, Cusson RM, et al. Kangaroo care: national survey of practice, knowledge, barriers, and perceptions. $M C N$ Am J Matern Child Nurs. 2002;27(3):146-153.

60. Chia P, Sellick K, Gan S. The attitudes and practices of neonatal nurses in the use of kangaroo care. Aust J Adv Nurs. 2006;23(4):20-27.

61. Harrison D, Bueno M, Adams-Webber T, Yamada J, Stevens B. Analgesic effects of sweet tasting solutions in infants: do we have equipoise yet? Presented at: 8th International Symposium on Pediatric Pain; March 7-11; 2010; Acapulco; Mexico.

62. Harrison D, Bueno M. Sweet solutions for pain in infants - how many studies are too many studies? Pain Res Manag. 2012;17(3):211, P134.

63. Blass E, Fitzgerald E, Kehoe P. Interactions between sucrose, pain and isolation distress. Pharmacol Biochem Behav. 1987;26(3): 483-489.

64. Blass EM, Shah A. Pain-reducing properties of sucrose in human newborns. Chem Senses. 1995;20(1):29-35.

65. Anseloni VC, Weng HR, Terayama R, et al. Age-dependency of analgesia elicited by intraoral sucrose in acute and persistent pain models. Pain. 2002;97(1-2):93-103.

66. Slater R, Fabrizi L, Worley A, Meek J, Boyd S, Fitzgerald M. Premature infants display increased noxious-evoked neuronal activity in the brain compared to healthy age-matched term-born infants. Neuroimage. 2010;52(2):583-589.

67. Barr RG. Reflections on measuring pain in infants: dissociation in responsive systems and "honest signalling". Arch Dis Child Fetal Neonatal Ed. 1998;79(2):F152-F156.

68. Anand KJ; International Evidence-Based Group for Neonatal Pain. Consensus statement for the prevention and management of pain in the newborn. Arch Pediatr Adolesc Med. 2001;155(2):173-180.

69. Bellieni CV, Taddio A, Linebarger JS, Lantos JD. Should an IRB approve a placebo-controlled randomized trial of analgesia for procedural pain in neonates? Pediatrics. 2012;130(3):550-553.

70. Bellieni CV, Buonocore G. Recommendations for an ethical treatment of newborns involved in clinical trials. Acta Paediatr. 2010; 99(1):30-32.

71. Barr RG, Quek VS, Cousineau D, Oberlander TF, Brian JA, Young SN. Effects of intra-oral sucrose on crying, mouthing, and hand-mouth contact in newborn and six-week old infants. Dev Med Child Neurol. 1994;36(7):608-618.

72. Harrison D, Loughnan P, Manias E, Gordon I, Johnston L. Repeated doses of sucrose in infants continue to reduce procedural pain during prolonged hospitalizations. Nurs Res. 2009;58(6):427-434. 
73. Mucignat V, Ducrocq S, Lebas F, Mochel F, Baudon JJ, Gold F. Effet analgésique de la crème Emla ${ }^{\circledR}$, du saccharose et de leur association pour les injections sous-cutanées chez le nouveau-né prématuré: étude prospective de 265 injections. [Analgesic effects of Emla ${ }^{\circledR}$ cream and saccharose solution for subcutaneous injections in preterm newborns: a prospective study of 265 injections]. Arch Pediatr. 2004;11(8): 921-925. French.

74. Stevens B, Yamada J, Beyene J, et al. Consistent management of repeated procedural pain with sucrose in preterm neonates: is it effective and safe for repeated use over time? Clin J Pain. 2005;21(6):543-548.

75. Johnston CC, Filion F, Snider L, et al. How much sucrose is too much sucrose? Pediatrics. 2007;119(1):226.

76. Taddio A, Shah V, Leung E, et al. Knowledge translation of the HELPinKIDS clinical practice guideline for managing childhood vaccination pain: usability and knowledge uptake of educational materials directed to new parents. BMC Pediatr. 2013;13:23.

77. Taddio A, Appleton M, Bortolussi R, et al. Reducing the pain of childhood vaccination: an evidence-based clinical practice guideline. CMAJ. 2010;182(18):E843-E855.

78. Registered Nurses' Association of Ontario. Assessment and Management of Pain. 3rd ed. Toronto, ON: Registered Nurses' Association of Ontario; 2013.
79. Spence K, Henderson-Smart D, New K, Evans C, Whitelaw J, Woolnough R; Australian and New Zealand Neonatal Network. Evidenced-based clinical practice guideline for management of newborn pain. J Paediatr Child Health. 2010;46(4):184-192.

80. Lee GY, Yamada J, Kyololo O, Shorkey A, Stevens B. Pediatric clinical practice guidelines for acute procedural pain: a systematic review. Pediatrics. 2014;133(3):500-515.

81. Gooding JS, Cooper LG, Blaine AI, Franck LS, Howse JL, Berns SD. Family support and family-centered care in the neonatal intensive care unit: origins, advances, impact. Semin Perinatol. 2011;35(1):20-28.

82. Health Canada. Family-Centred Maternity and Newborn Care: National Guidelines. Ottawa, ON: Minister of Public Works and Government Services; 2000

83. Franck LS, Oulton K, Bruce E. Parental involvement in neonatal pain management: an empirical and conceptual update. J Nurs Scholarsh. 2012;44(1):45-54.

84. Franck LS, Oulton K, Nderitu S, Lim M, Fang S, Kaiser A. Parent involvement in pain management for NICU infants: a randomized controlled trial. Pediatrics. 2011;128(3):510-518.

85. Ranger M, Grunau RE. Early repetitive pain in preterm infants in relation to the developing brain. Pain Manag. 2014;4(1):57-67.

\section{Publish your work in this journal}

Research and Reports in Neonatology is an international, peer-reviewed, open access journal publishing original research, reports, editorials, reviews and commentaries on neonatal health. The manuscript management system is completely online and includes a very quick and fair peer-review system. Visit http://www.dovepress.com/testimonials.php to read real quotes from published authors. 